Rev Inv Vet Perú 2004; 15 (1): 25-36

\title{
CARACTERIZACIÓN DE LAS LESIONES ENCONTRADAS EN BOVINOS CON HEMATURIA VESICAL ENZOÓTICA EN LA ZONA DE OXAPAMPA, PASCO
}

\author{
Christian Gonzáles E. ${ }^{1}$, Alfonso Chavera C. ${ }^{2,3}$. Rosa Perales C. ${ }^{2}$, Néstor Falcón P. ${ }^{4}$ y \\ Roberto Evaristo R. ${ }^{5}$
}

\section{Abstract}

An anatomo-histopathologic study of the urinary bladder, liver, kidney and spleen from 41 Zebu and crossbreed cattle with different lesions of a disease commonly named as "hematuria" or Machicura's intoxication was carried out in the Oxapampa province (Pasco). A total of 173 animals were inspected and samples from 41 animals with pathological lesions in bladder were collected at the local slaughterhouse. It was found that urinary bladder lesions were multifocal in $85.4 \%$ (35/41) of the cases. Tissue samples were processed with Hematoxiline-Eosine stain (HE), Hale's histochemical stain for acid mucopolysaccharide and Masson trichromic for fibrous connective tissue with collagen or muscular fibres. The most important microscopic lesions were proliferative polips (24/ $41)$; the circulatory processes as haemorrhage (28/41), vascular proliferation or "angioblastic nests" (19/41), and inflammatory processes as the non suppurative cystitis (29/41). Neoplasias were found in the $68.3 \%$ of the cases $(28 / 41)$, where $41.7 \%$ had epithelial origen and $58.3 \%$ were of non epithelial type. The epithelial types were represented by the in situcarcinoma (11/41) and mucous papilloma (4/41), whereas the hemangiosarcoma (14/41), hemangioma (10/41) and mixosarcoma (6/41) were the most frequent non epithelial neoplasias. Single cases of racemous papilloma, squamous cell carcinoma, tubular carcinoma, rhabdomyosarcoma, leiomyosarcoma, hemangiopericytosarcoma, lymphoma, and a lymphoid metastasis were observed. It is concluded that the well known process of "hematuria" corresponded to Bovine Enzootic Hematuria.

Key words: "hematuria", Bovine Enzootic Vesical Haematuria, urinary bladder, histopathology, neoplasia, Pteridium aquilinum

\section{RESUMEN}

Se realizó el estudio anátomo-histopatológico de muestras de vejiga urinaria, así como de hígado, riñón y bazo de vacunos con lesiones de una enfermedad conocida en la provincia de Oxapampa (Pasco) como "Hematuria" o "Intoxicación por Machicura". Las muestras se obtuvieron de 41 animales con lesiones en vejiga urinaria a partir de la

\footnotetext{
${ }^{1}$ Practica privada

${ }^{2}$ Laboratorio de Histo-Patología Animal, FMV-UNMSM

${ }^{3}$ E-mail: achavera03@yahoo.com

${ }^{4}$ Laboratorio de Medicina Veterinaria Preventiva, FMV-UNMSM

${ }^{5}$ Clínica de Animales Mayores, FMV-UNMSM
} 
inspección de 173 animales en el Camal Municipal de Oxapampa. En el diagnóstico histopatológico se emplearon las tinciones de Hematoxilina-Eosina e histoquímicas de Hale para mucopolisacáridos ácidos y tricrómico de Masson para tejido conectivo fibroso y muscular con presencia de colágeno. Las lesiones halladas en la vejiga urinaria fueron multifocales en el $85.5 \%$ (35/41) de los casos, siendo las más frecuentes las formaciones nódulo-vasculares ulceradas. Las lesiones microscópicas corresponden a procesos proliferativos donde destacaron los polipoides (24/41), procesos circulatorios como los hemorrágicos (28/41) y las yemas de proliferación vascular o "nidos angioblásticos" (19/41) y procesos inflamatorios como la cistitis no supurativa (29/41). Los procesos neoplásicos se presentaron en el $68.3 \%$ (28/41), siendo el $41.7 \%$ de tipo epitelial y el $58.3 \%$ no epitelial. Los epiteliales estuvieron representados por carcinomas in situ (11/ 41) y papilomas mucosos (4/41), mientras que el hemangiosarcoma (14/41), hemangioma (10/41) y mixosarcoma (6/41) fueron los neoplasmas no epiteliales más frecuentes. Se registró un solo caso de papiloma racemoso, rabdomiosarcoma, leiomiosarcoma, hemangiopericitosarcoma, carcinoma tubular, carcinoma escamoso, linfoma y una metástasis linfoide. Se concluye que el proceso conocido como "hematuria" en Oxapampa corresponde a la hematuria vesical enzoótica bovina.

Palabras clave: "hematuria", Hematuria Vesical Enzoótica Bovina, vejiga, histopatología, neoplasia, Pteridium aquilinum

\section{INTRODUCCIÓN}

La ganadería bovina de tipo extensiva es una de las principales actividades económicas de la provincia de Oxapampa, Pasco. Sin embargo, el desarrollo ganadero de esta región se encuentra limitado por una enfermedad que se caracteriza por hemorragias a nivel de la vejiga urinaria, denominada comúnmente como "hematuria", "orina con sangre" o "intoxicación por machicura". Esta enfermedad sería la Hematuria Vesical Enzoótica Bovina (HVEB), que es un proceso no infeccioso que afecta a los bóvidos (domésticos y silvestres) en crianza al pastoreo, circunscrita a zonas geográficas específicas, y que ha sido reportada en diversas partes del mundo tropical.

Esta enfermedad está relacionada al consumo, por largos periodos, del helecho común, elPteridium aquilinum (Wiesner, 1973). Actualmente se le denomina a este síndrome: "Intoxicación por Ptaquilósido" (Radostits et al., 2002), en alusión a la principal molécula carcinogénica del $P$. aquilinum (Niwa et al., 1983), la cual ge- neraría los procesos neoplásicos y noneoplásicos de esta enfermedad en la vejiga del bovino. Por otro lado, Campo et al. (1992) ha relacionado como posibles etiologías de esta enfermedad a virus de la familia Papovaviridae.

En fases iniciales de la enfermedad ocurre una microhematuria que puede ser imperceptible (estadio subclínico); y progresivamente la orina se torna oscura, pasando por emisiones enrojecidas intermitentes o macrohematuria (estadio clínico) (Jubb et al., 1991). El animal puede llegar a eliminar por esta vía una gran cantidad de coágulos de sangre, lo cual irá acompañado de debilidad general, mucosas pálidas, anemia, emaciación, caída de los niveles de producción de leche, disuria, tenesmo, posición de falsa xifosis, cuadros obstructivos uretrales, uremia y finalmente la muerte. Los animales pueden tener periodos sin hematuria (Marcal y Gaste, 1991; Radostits et al., 2002).

Este proceso posee un gran impacto económico. En Colombia se calcula que 30,000 cabezas de ganado en edad productiva, tienen que ser beneficiadas anualmente, por lo que dejan de producir cerca de 24.5 
millones de litros de leche, que se traduce en pérdidas económicas superiores a los $6 \mathrm{mi}$ llones de dólares (Torres, 1990). Las complicaciones con la HVEB alcanzan a la salud pública, donde investigaciones de AlonsoAmelot et al. (1996), reportan que la leche de las vacas con esta enfermedad son un factor de riesgo para la ocurrencia de cáncer en humanos. En el Perú, no se tiene mucha información referente a esta toxicosis; pero se puede mencionar las experiencias de Gonzáles y Carpio (1973) quienes reportaron un caso de hematuria vesical crónica en Pucallpa; así como las de Velarde (1991) quien hace una descripción clínica del proceso en los valles del Huallaga y del Pichis Palcazu, y las de López (1983) que encuentra una incidencia de $16 \%$ en el valle de Oxapampa. Por estas razones, se planteó el presente estudio con el objetivo de realizar una caracterización anátomo-histopatológica de las lesiones que ocasiona la denominada "hematuria", a partir de muestras de tejidos obtenidas en el Camal Municipal de Oxapampa.

\section{Materiales y Métodos}

\section{Lugar de estudio}

El estudio se realizó en el Camal Municipal de la ciudad de Oxapampa, capital de la provincia del mismo nombre, perteneciente a la Región Pasco, y en el Laboratorio de Histopatología de la Facultad de Medicina Veterinaria, Universidad Nacional Mayor de San Marcos, Lima.

\section{Tamaño de la muestra}

El Teorema del Límite Central de Teoría Avanzada de Probabilidades afirma que la precisión de la muestra mejora al crecer la $\mathrm{N}$ (tamaño muestral), y que en el caso de valores grandes viene a ser ?30 (Spiegel, 1991). Es así que se consideró 30 como la cantidad mínima significativa para realizar la caracterización anátomo-histopatológica.
Se inspeccionó a 173 bovinos en el Camal Municipal de Oxapampa (un promedio de 5 animales por día de matanza) y se colectó muestras a 41 animales que presenta ron lesiones inespecíficas en la mucosa vesical.

\section{Características de las muestras}

Se tomaron muestras de vejigas urinarias con lesiones macroscópicas inespecíficas en la superficie de la mucosa. Asimismo, a estos animales se les colectó muestras de hígado, bazo y riñón y nódulos linfáticos. En el caso que la vejiga tuviese contenido (mayormente se encontraba vacía), se procedió a tomar una muestra de orina para verificar la presencia de glóbulos rojos en el sedimento.

\section{Análisis histopatológico}

Las muestras histopatológicas se trabajaron con la coloración rutinaria de Hematoxilina-Eosina (HE), y de ser necesario, se realizaron coloraciones histoquímicas, utilizando las técnicas de Hale para mucopolisacáridos y tricrómico de Masson para tejido conectivo fibroso o muscular, con presencia de colágeno.

\section{Resultados}

\section{Evaluación macroscópica}

Vejiga

Las lesiones fueron de tipo multifocal en el $85.4 \%$ de las muestras colectadas. Otros tipos de lesiones halladas fueron las formaciones nodulares prominentes sobre la mucosa del órgano y numerosos vasos tortuosos reticulares proliferando el subepitelio, de aproximadamente $1-2 \mathrm{~cm}$ de diámetro, que al corte mostraban una mucosa proliferada hacia la luz, de color oscuro y vascularizada, sustentada en el corion. Se encontró además procesos verrucoides o papilomatosos, de 
Cuadro 1. Lesiones microscópicas en vejiga de bovinos con Hematuria Vesical Enzoótica

\begin{tabular}{lcc}
\hline Tipo de lesión & $\begin{array}{c}\text { Casos } \\
(\mathrm{n})\end{array}$ & $\begin{array}{c}\text { Frecuencia } \\
(\%)\end{array}$ \\
\hline Formaciones nodulares fijadas a la mucosa & 34 & 82.9 \\
Formaciones verrucoides & 17 & 41.5 \\
Mucosa enrojecida & 24 & 58.5 \\
Extravasación vascular & 27 & 65.9 \\
Pared vesical engrosada & 24 & 58.5 \\
Degeneración de la mucosa & 10 & 24.4 \\
Macro-nodulaciones pediceladas & 2 & 4.9 \\
Masas gelatinosas rojo oscuro en el lumen & 3 & 7.3 \\
\hline
\end{tabular}

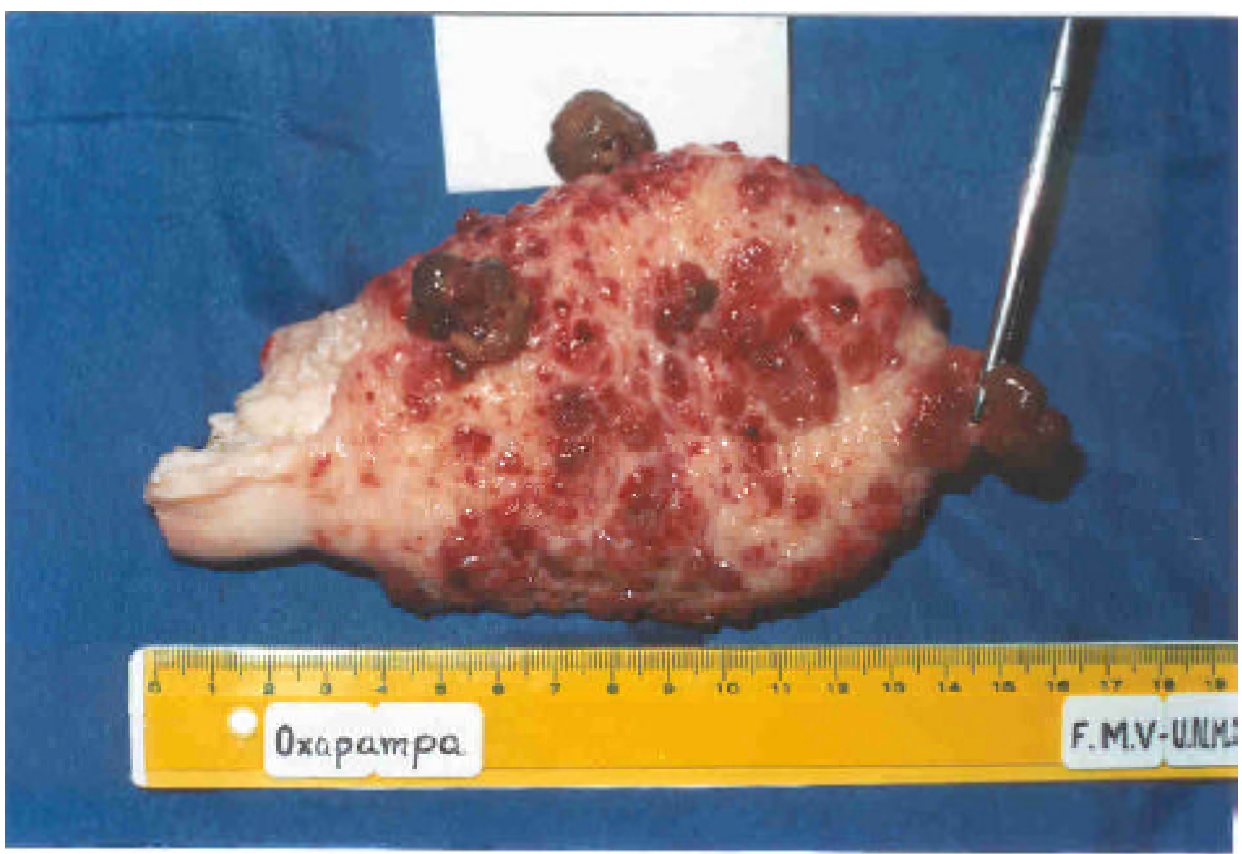

Figura 1. Múltiples nodulaciones de $2.0 \mathrm{~cm}$ de diámetro y hemorragia difusa

color nacarado, de 0.3 a $1.0 \mathrm{~cm}$ de longitud, que al corte presentaron una mucosa replegada, arborizada, proliferada hacia la luz, con un pedicelo delgado fijado firmemente al corion. Otras lesiones observadas en la superficie de la mucosa fueron focos rojizos de extravasación sanguínea de $0.1-0.5 \mathrm{~cm}$ de diámetro, de color rojo brillante y con engrosamiento del corion y de la zona muscular.
En los casos más severos se encontró múltiples proliferaciones sobre la mucosa en forma de coliflor y nódulos firmes con tendencia a coalescer, mostrando en ambos casos soluciones de continuidad superficiales, repliegues y focos de extravasación sanguínea, que conllevaron a una pérdida total de su arquitectura macroscópica. Al corte, ambas estructuras evidenciaron crecimiento ar- 
Cuadro 2. Frecuencia de tipos de neoplasmas epiteliales y no epiteliales en vejiga de bovinos con Hematuria Vesical Enzoótica

\begin{tabular}{lrrllcr}
\hline \multirow{2}{*}{ Neoplasmas Epiteliales } & \multicolumn{2}{c}{ Ocurrencia } & & Neoplasias No Epiteliales & \multicolumn{2}{c}{ Ocurrencia } \\
\cline { 2 - 3 } \cline { 6 - 8 } & \multicolumn{1}{c}{$\mathrm{n}$} & $\%$ & & $\mathrm{n}$ & $\%$ \\
\hline Carcinoma transicional & 4 & 9.8 & & Hemangioma & 10 & 24.4 \\
Carcinoma in situ & 11 & 26.8 & & Hemangiosarcoma & 14 & 34.2 \\
Carcinoma papilar & 3 & 7.3 & & Hemangiopericitosarcoma & 1 & 2.4 \\
Carcinoma escamoso & 1 & 2.4 & & Mixosarcoma & 6 & 14.6 \\
Carcinoma tubular & 1 & 2.4 & & Rabdomiosarcoma & 1 & 2.4 \\
Papiloma mucoso & 4 & 9.8 & & Leiomiosarcoma & 1 & 2.4 \\
Papiloma racemoso & 1 & 2.4 & & Linfoma & 1 & 2.4 \\
& & & & Metástasis linfoide & 1 & 2.4 \\
\hline \multicolumn{1}{c}{ Total: } & 25 & 41.7 & & Total: & 35 & 58.3 \\
\hline
\end{tabular}

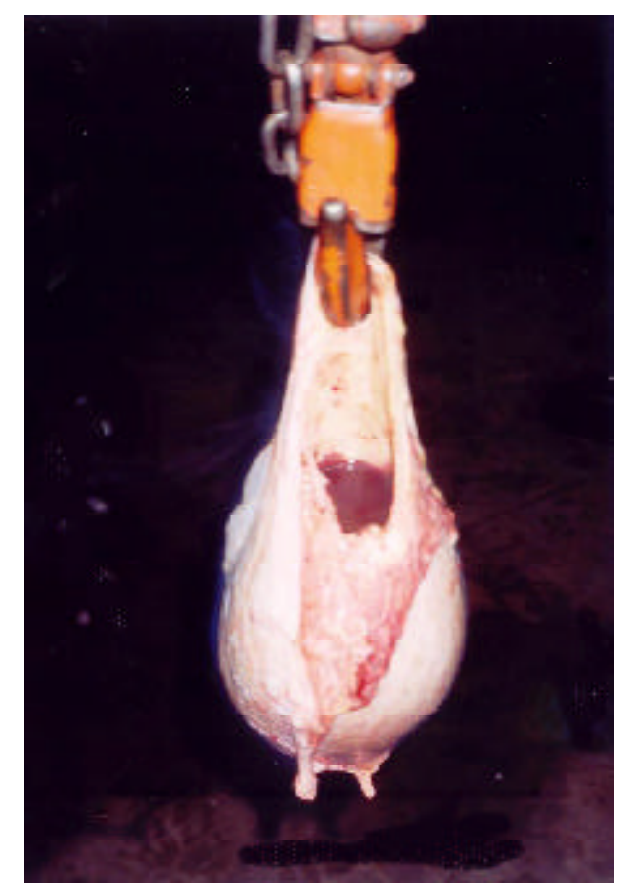

Figura 2. Órgano distendido con contenido hematúrico

borescente en forma de coliflor, resistencia por el engrosamiento de su pared orgánica, así como una evidente actividad vascular por la coloración de las prominencias, pero sin exudación. Por otro lado, dentro de las lesiones macroscópicas más singulares se encon- traron nodulaciones de color verde-claro a verde-negruzco, de 1.5-2.0 $\mathrm{cm}$ de longitud, de apariencia encapsulada, de consistencia sólida, pero friable al corte, y fijas a la mucosa vesical por un pedicelo muy delgado, pero resistente a la tracción del corte (Fig. 1). 
Se observó la presencia de masas gelatinosas de un color rojo oscuro (con pesos superiores a los $500 \mathrm{~g}$ ), de olor ofensivo, contenidas en el lumen vesical y que estarían produciendo un cuadro obstructivo, hecho que tendría repercusión directa en la severidad de la enfermedad (Cuadro 1, Fig. 2).

\section{Hígado}

En el parénquima (en uno o varios lobulillos hepáticos), se observaron múltiples focos de consistencia dura, en forma encapsulada, que al corte mostraron la presencia de un parásito de forma foliar, de 1.0$2.0 \mathrm{~cm}$ de longitud. Estos hallazgos ocurrieron mayormente en ganado procedente de los distritos de mayor altitud sobre el nivel del mar de la provincia de Oxapampa (Oxapampa y Chontabamba).

\section{Riñón y bazo}

Se encontraron pocas alteraciones macroscópicas. Entre ellas la escasa delimitación entre corteza y médula renal, y se puede mencionar la presencia de bordes romos en el bazo.

\section{Hallazgos adicionales}

En dos casos se notó la presencia de nódulos linfáticos (un iliaco y un mediastínico) aumentados de tamaño, dejando fluir al corte una sustancia líquida rojiza.

\section{Descripción histopatológica}

Vejiga

Destacaron las formaciones polipoides, que son proyecciones de la mucosa vesical hacia la luz del órgano, encontradas en el $58.5 \%$ de las observaciones. Se encontró, además, proliferaciones quísticas, es decir, formaciones esféricas presentes en la mucosa vesical, que al corte mostraba una luz interior con presencia de una sustancia hialina, con características proteináceas en algunos casos. Se registró agrupaciones de células de la mucosa, a las cuales se les denominó nidos epiteliales. En el corion vesical se reportó la presencia de unas estructuras con características de glándulas secretoras funcionales; es decir, múltiples acinis lográndose apreciar en algunos casos un conducto secretor, de allí que se les denominó formaciones acinares.

En 28 de los 38 animales positivos a HVEB se diagnosticaron procesos neoplásicos $(68.3 \%)$. De estos, el $41.7 \%$ fue de tipo epitelial y el $58.3 \%$ de tipo no epitelial; es decir, de diferente tipo o de otra derivación de hoja blastodérmica. Se diagnosticaron 15 tipos de neoplasias, siendo las más comunes el hemangiosarcoma (34.2\%, Fig. 3) carcinomas in situ (26.8\%, Fig. 4) y hemangiomas (24.4\%, Fig. 5). Asimismo, pero en menor cuantía, se presentaron mixosarcomas (Fig. 6), papilomas mucosos, carcinomas transicionales y papilares (Cuadro 2).

En el $34.2 \%$ de vejigas con neoplasias se encontró 2 tipos de neoplasias presentes en la misma vejiga (Cuadro 3).

Cuadro 3. Frecuencia de neoplasmas múltiples en vejiga de bovinos con Hematuria Vesical Enzoótica

\begin{tabular}{crr}
\hline $\begin{array}{c}\mathrm{N}^{\mathbf{o}} \text { de neoplasias } \\
\text { vesicales por vejiga }\end{array}$ & $\mathrm{N}^{\mathbf{0}}$ & $\%$ \\
\hline 1 & 8 & 19.5 \\
2 & 14 & 34.2 \\
3 & 3 & 7.3 \\
5 & 3 & 7.3 \\
\hline Total & 28 & 68.3 \\
\hline
\end{tabular}

Las lesiones circulatorias más frecuentes fueron la extravasación vascular difusa (68.3\%) y los "nidos angioblásticos" que son unas estructuras conformadas por vasos sanguíneos en proliferación.

Dentro de los procesos inflamatorios, resultó importante el hallazgo del 70.7\% de cistitis no supurativa crónica, con la submuco- 


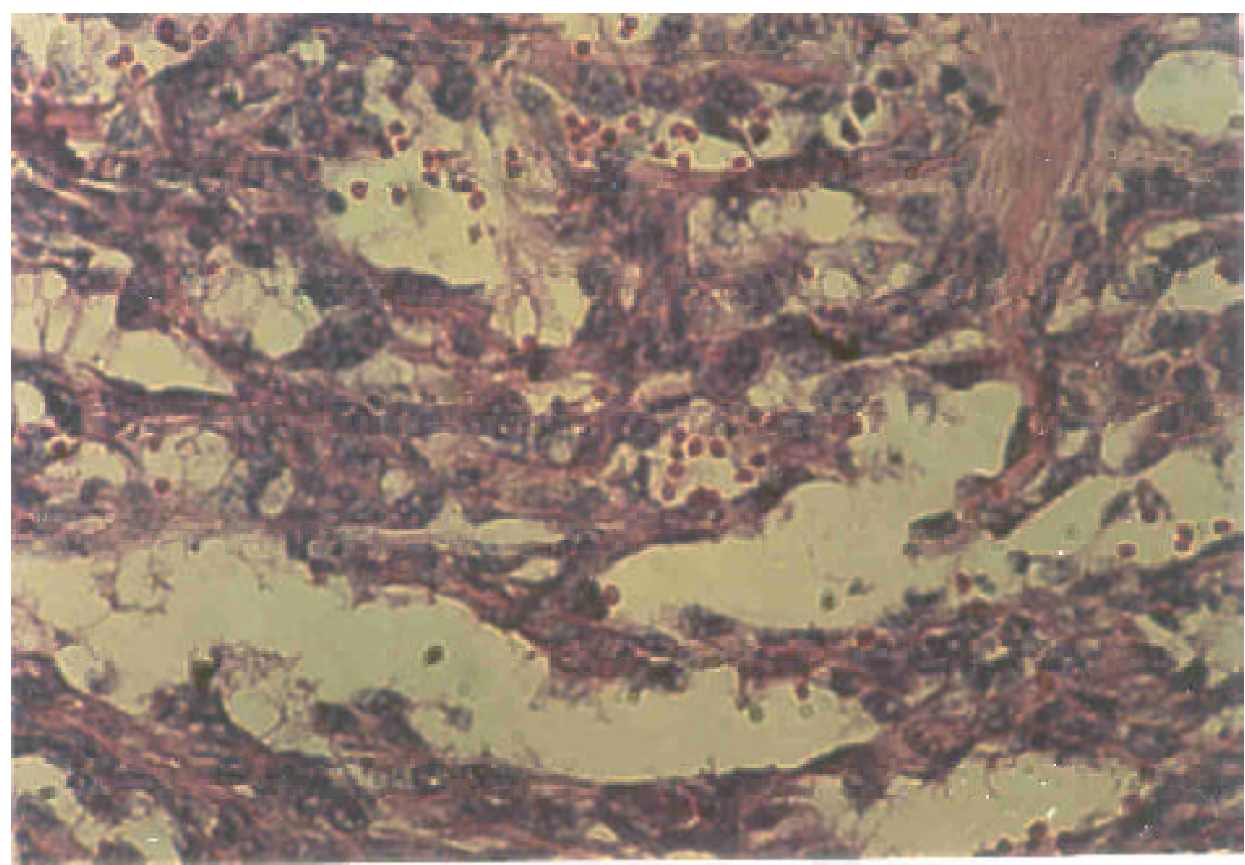

Figura 3. Hemangiosarcoma (250x)

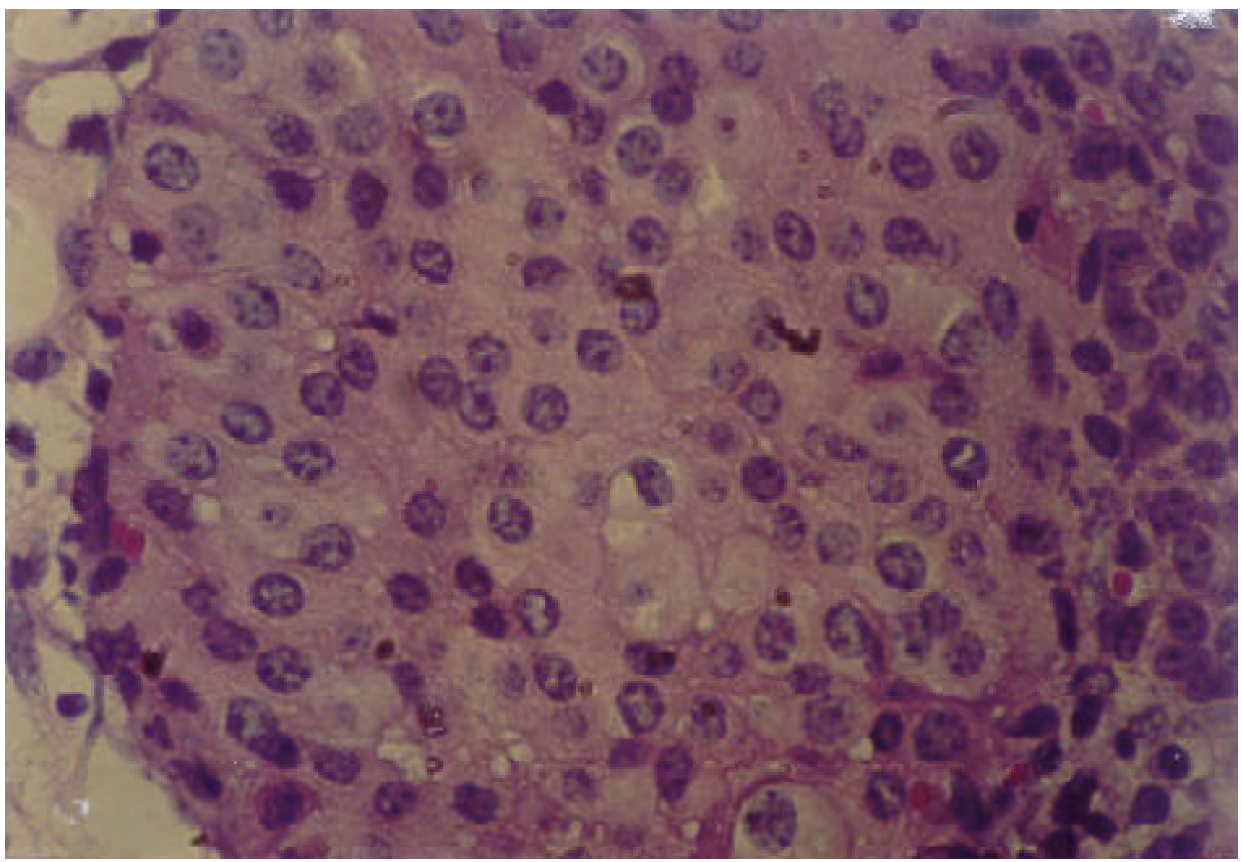

Figura 4. Carcinoma transicional in situ (400x) 


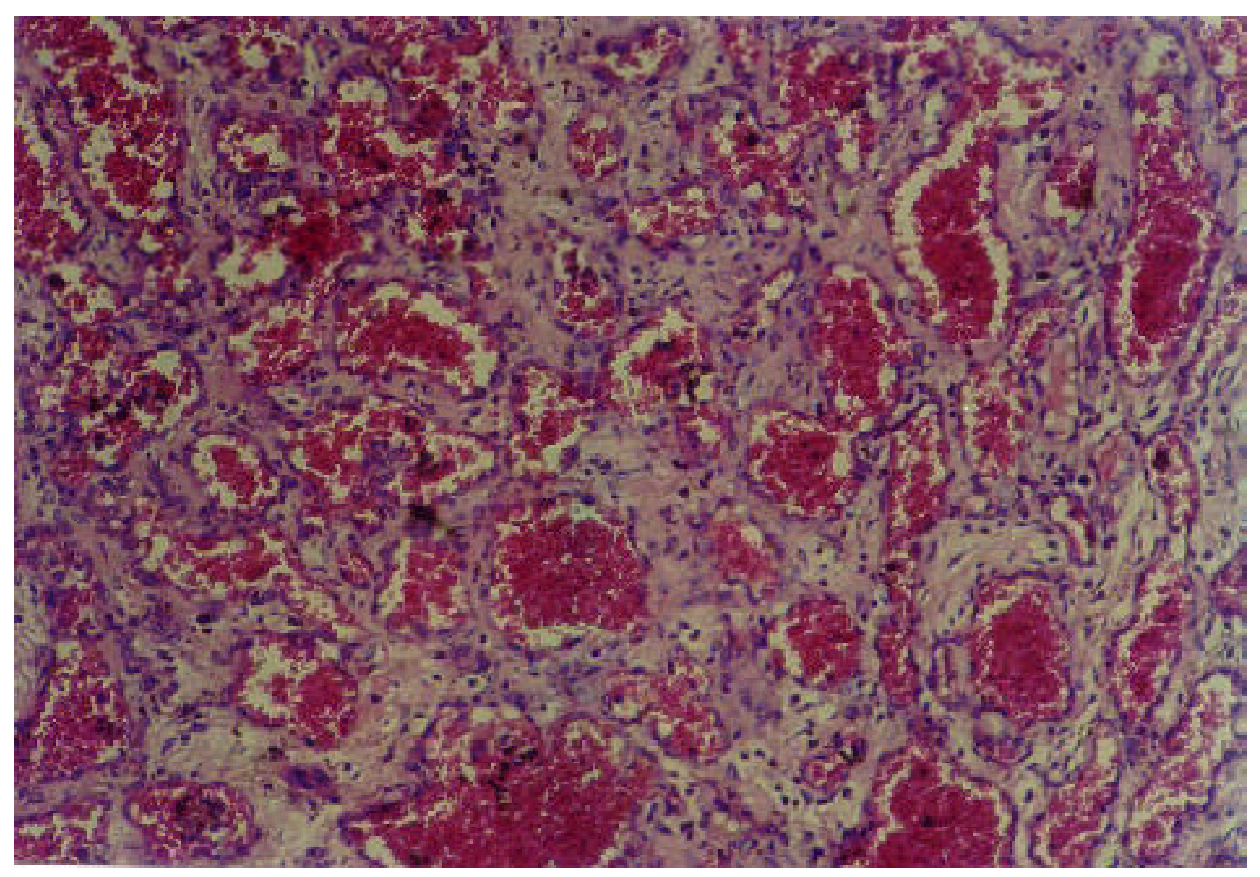

Figura 5. Hemangioma (40x)

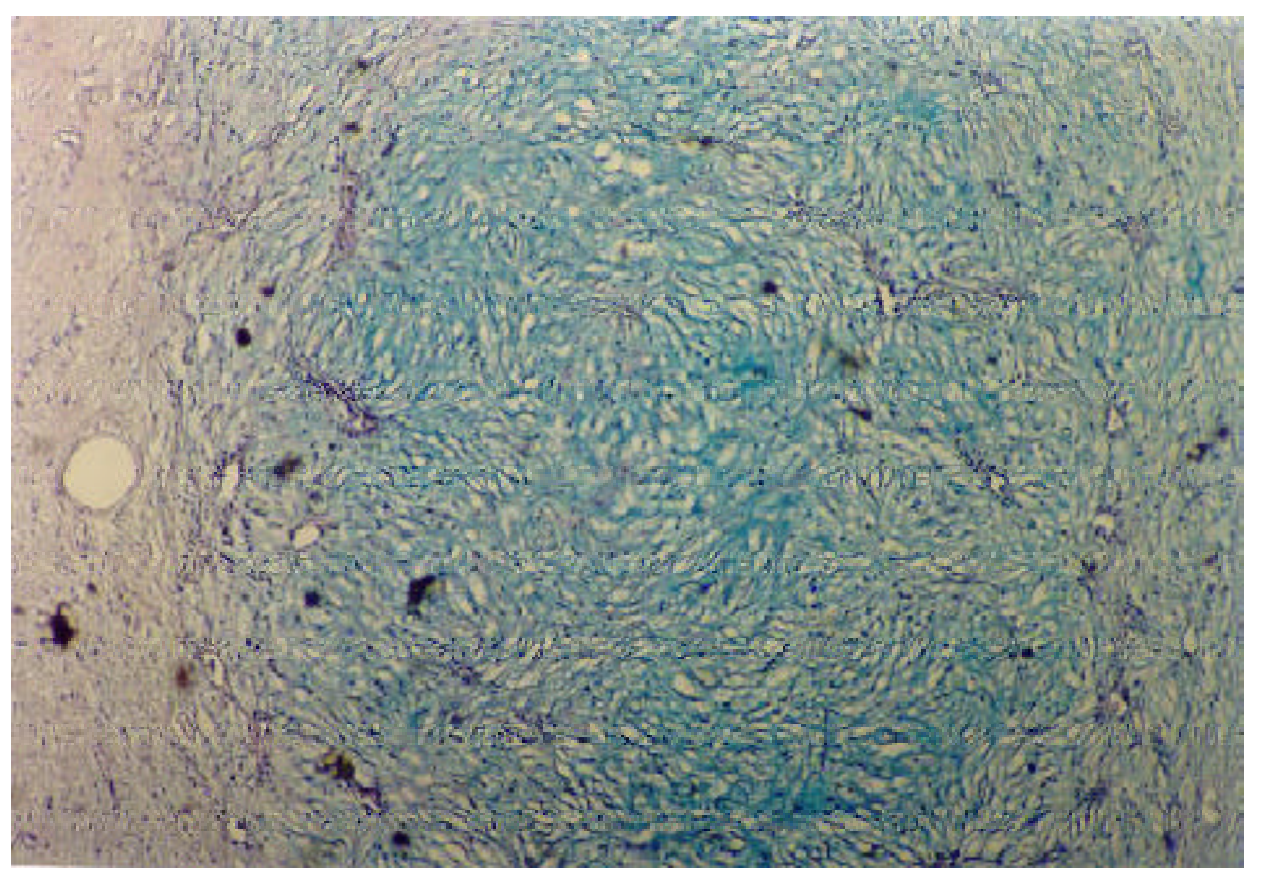

Figura 6. Mixosarcoma - Coloración de Hale (40x) 
sa caracterizada por la presencia de linfocitos agrupados en grandes cantidades en forma de "folículos", además de células plasmáticas, macrófagos, edema, fibroplasia, y descamación del epitelio de la mucosa. También se encontró otro tipo de exudados, como el conformado por polimorfonucleares neutrófilos asociado a úlcera hemorrágica.

\section{Hígado}

Las lesiones más frecuentes fueron la presencia de hepatocitos hinchados (edema celular o tumefacción turbia) con la pérdida de la trabecularidad normal del órgano (63.4\%); focos de reacción inflamatoria mononuclear o linfo-plasmocítica $(56.1 \%)$, con una ubicación a nivel periportal o portal ("triaditis"), y que están encerrando las hepatitis no supurativas multifocales o focales crónicas. Además, se presentaron tres casos de lesiones importantes: un hemangioma cavernoso asociado a masas de fibrina, glóbulos rojos y linfocitos en organización y adheridos a un endotelio, que se mostraba homogéneo por zonas, aunque en otras se notaba más aplanado; en otro caso, la presencia de dilatación vascular no neoplásica; y finalmente, el hallazgo de tejido muscular en el hígado (en vecindad con una cápsula engrosada).

\section{Riñón y bazo}

Las lesiones más frecuentes en riñón fueron la presencia de reacción inflamatoria mononuclear (63.4\%), lo cual indica la ocurrencia de nefritis agudas; y la hinchazón del epitelio tubular con el citoplasma vacuolado $(34.2 \%)$.

La lesión más común en el bazo fue la depleción de las células linfoides foliculares que conforman la pulpa blanca. Otras lesiones fueron edema intrafolicular y células con características de atipia, así como figuras de mitosis compatibles con una linfomatosis esplénica incipiente.

\section{Metástasis}

En una muestra de bazo y de nódulo linfático iliaco del mismo animal, se registró la presencia de un área de proliferación de vasos sanguíneos alterados, con células endoteliales anaplásicas que corresponden a un caso de hemangiosarcoma; el cual coincide con el hallado en su correspondiente vejiga (la lesión primaria), siendo el único caso de metástasis de origen vesical en el presente estudio. Este nódulo linfático iliaco mostró además folículos linfoides hiperplásicos, con linfocitos atípicos aumentados de tamaño, de núcleos prominentes y múltiples figuras de mitosis, compatibles con linfosarcoma.

\section{Discusión}

La literatura científica indica que las lesiones vesicales son características permanentes en los animales con HVEB, a diferencia del signo clínico de hematuria que puede desaparecer por periodos de tiempo variables; sea esto cuando se le aplican tratamientos con antibióticos y antihemorrágicos, cuando se le retira de los pastizales problema, o simplemente por una respuesta temporal del organismo, pero sin llegar a la curación del proceso.

Las lesiones que pueden ser encontradas en los casos de HVEB resultan muy variadas, pues en una misma vejga pueden coincidir alteraciones o procesos que difícilmente se presentan asociadas en otras patologías del bovino. Así tenemos que los procesos inflamatorios con exudados no supurativos estuvieron presentes de manera frecuente, lo que posiblemente indica que la mucosa vesical estuvo sometida a cuadros crónicos de inflamación constante, posiblemente por agentes externos presentes en la orina.

Las vejigas colectadas presentaron en su mayoría lesiones multifocales, estando entre ellas las que poseían cuadros de hemorragias, formaciones papilomatosas o 
verrucoides, similar a lo reportado por Marín (2001). Los casos con mayores lesiones histopatológicas se presentaron en vejigas con alteraciones severas de su arquitectura macroscópica; tal es el caso de las que poseían "quistes macroscópicos pedunculados", o estructuras en forma de "coliflor", de manera similar a lo descrito por Mugera y Nerito (1968) y Moulton (1978).

Los cambios o procesos proliferativos estuvieron presentes dentro de los hallazgos histopatológicos de manera constante. Entre estos se encuentran tanto la formación polipoide y la proliferación quística en la mucosa como los nidos epiteliales y estructuras acinares en la lámina propia; los cuales coinciden con Pamukcu (1974), quien denomina a estas lesiones como cistitis polipoide, cistitis quística, nidos de Vonn Brunn's y metaplasia glandular, respectivamente. Este autor menciona que estas lesiones se pueden encontrar sin la necesidad de haber una neoplasia, como lo hallado en muchos de los casos de la presente investigación. El único cambio proliferativo que refiere el autor en mención, pero que no fue encontrado en el presente estudio, fue la metaplasia escamosa con presencia de queratina. Olson et al. (1965) y Brobst y Olson (1965) en sus trabajos de inducción experimental de neoplasias mencionan que hallaron metaplasia glandular en el 38 y $66 \%$ de sus casos, respectivamente, en tanto que en el presente estudio se encontró en el $17.1 \%$.

Una de las características más importantes de la HVEB es la gran actividad vascular que presenta. El proceso circulatorio microscópico más frecuente fue la hemorragia cística difusa (68.3\% de los casos), similar a lo encontrado macroscópicamente entre petequias y equimosis (65.9\%). Dentro de estas hemorragias se debe resaltar las de tipo transepitelial, de las cuales no existen reportes anteriores y que si bien se presentaron solo en cinco casos (12.2\%), muestran una imagen histopatológica muy particular que estaría relacionada con el cuadro clínico de microhematuria, que ha sido descrita en la fases iniciales de la HVEB (Jubb et al., 1991).

Los hallazgos más importantes resultaron ser unas estructuras conformadas por vasos sanguíneos tortuosos, en proliferación, localizados en la lámina propia, que no han sido descritas previamente. Por sus características, se ha considerado denominarlos como "nidos angioblásticos", los cuales se presentaron en 19 casos (46.3\%) y estarían siendo la fuente de futuros procesos neoplásicos vasculares o entes nutricios de neoplasias de otras estirpes, pero que definitivamente denotan una actividad celular endotelial exacerbada. Otros procesos importantes encontrados, fueron la telangiectasia y la trombosis, los cuales también tienen mucha relación con las alteraciones del endotelio vascular propias de la patología vesical, y las cuales podrían presentarse en fases tanto iniciales como finales de la enfermedad.

El hemangiosarcoma fue el tipo de neoplasia más frecuente en este estudio (36.8\%) a diferencia de los hallazgos de Moulton (1978). Asimismo, la frecuencia de hemangiomas $(24.4 \%)$ fue inferior a lo reportado por Olson et al. (1965), Mugera y Nerito (1968) y Marín (2001), quienes encontraron frecuencias de 68,55 y $86 \%$, respectivamente.

La frecuencia de carcinomas transicionales (in situ, propiamente dichos y papilares), llegó al 43.9\%, cifra inferior a otros reportes (Pamukcu et al., 1976). En forma similar, la presencia de papilomas mucosos de pequeña dimensión, así como de un papiloma racemoso de gran tamaño ocurrió en menor proporción a lo hallado por Pamukcu et al. (1976), quien encontró en casos naturales de HVEB hasta un $24 \%$ de papilomas. Este hallazgo corrobora lo mencionado por Villafañe et al. (1979) y Campo et al. (1992), respecto a una posible interrelación viral en el desarrollo de la HVEB.

Como aportes del presente estudio a la gama de las neoplasias de la HVEB se debe mencionar el hallazgo de mixosarcomas, corroborados por coloración histoquímica de 
Hale (14.6\%), rabdomiosarcoma y leiomiosarcoma (identificados mediante el uso de la coloración histoquímica de Tricrómico de Masson), hemangiopericitosarcoma, carcinoma escamoso y carcinoma tubular. Asimismo, se observó en la vejiga un linfoma y una metástasis linfoide (de origen no definido), los cuales tendrían relación con lo reportado por Pamuku et al. (1972), quienes mencionaron que el helecho consumido por periodos largos produciría alternaciones linfocitarias que conducirían a un cuadro de leucosis, aunque también podrían estar relacionadas a un caso de Leucosis Bovina Enzoótica, dada su alta incidencia en el país.

Es importante resaltar la presentación de casos con neoplasias múltiples, incluyendo 3 casos con 5 tipos de neoplasmas de distinto origen (epiteliales y mesenquimales), así como las mixtas (neoplasias epiteliales y noepiteliales en la misma vejiga), lo cual refleja una marcada alteración de los procesos celulares normales, pues estas neoplasias en la mayoría de los casos muestran una clara tendencia hacia la malignidad. Esta situación no se observa en otra patología del bovino y es probable que sea único en la naturaleza.

El hallazgo más importante en el hígado fue un hemangioma cavernoso con trombosis, de manera similar a lo reportado por Mugera y Nerito (1968), y que puede considerarse dentro de la actividad endotelial anómala que presenta la HVEB. En el riñón, las lesiones encontradas resultaron bastante inespecíficas. Destacó la reacción inflamatoria crónica a nivel de túbulos y/o periglomerular, en tres casos, lo que podría tener relación con los procesos obstructivos de la vejiga y proliferación bacteriana.

La alteración histopatológica más frecuente en el bazo fue la depleción linfoide. Esto se puede relacionar con el hallazgo clínico de severa linfopenia, que refiere Radostits et al. (2002).
La presencia de procesos neoplásicos, proliferativos, "nidos angioblásticos", y demás alteraciones observadas en la HVEB, vienen a ser indicadores de una marcada alteración de los procesos celulares normales, los cuales estarían siendo causados por una o varias sustancias carcinogénicas. Entre ellas puede ser el ptaquilósido proveniente del Pteridium aquilinum (Niwa et al., 1983), que actuaría deteniendo el proceso de muerte celular programada o apoptosis como refiere AlonsoAmelot (1999); conduciendo a la célula a elevar su metabolismo interno y a proliferar descontroladamente.

De los 41 animales "sospechosos" que formaron parte del presente estudio, en 38 de ellos se obtuvo la suficiente evidencia para considerarlos como positivos a Hematuria Vesical Enzoótica Bovina (HVEB) luego del diagnóstico histopatológico. Los tres casos restantes fueron considerados como negativos, debido a que las vejigas presentaban escasas lesiones características de la HVEB que la literatura refiere, aunque podrían ser casos demasiados primigenios de la enfermedad en mención.

\section{Conclusiones}

? La enfermedad conocida como "hematuria" por los ganaderos de la provincia de Oxapampa corresponde a la Hematuria Vesical Enzoótica Bovina (HVEB).

? Las principales lesiones que presenta la HVEB se encuentran en la vejiga y son de naturaleza muy diversa, tanto en lo referente a procesos neoplásicos, proliferativos y vasculares, lo cual es una característica patognomónica de esta enfermedad.

? La actividad celular en las muestras de animales positivos a HVEB denota una tendencia a la disfuncionalidad tisular, que indicaría una etiología de carcinógenos muy potentes por las lesiones encontradas en las vejigas. 


\section{Literatura Citada}

1. Alonso-Amelot, M.E. 1999. Helecho macho, salud animal y salud humana. Rev. Fac. Agron. LUZ (Venezuela) 16: 528-541.

2. Alonso-Amelot, M.E; U. Castillo; B.L. Smith; D.R. Lauren. 1996. Bracken ptaquiloside in milk. Nature 382.

3. Brobst, D.F.; C. Olson. 1965. Histopathology of urinary bladder tumors induced by bovine cutaneous papilloma agent. Cancer Research 25: 12-19.

4. Campo, M.S.; W.F. Jarret; R. Barron; B.W. O'Neil; K.T. Smith. 1992. Association of bovine papillomavirus type 2 and bracken fern with bladder cancer in cattle. Cancer Research 52: 6898-6904.

5. Gonzales, S.; M. Carpio 1973. Informe de un caso de hematuria vesical crónica bovina en la selva peruana. Rev. Inv. Pec. (Perú) 2: 109.

6. Jubb, K.; P. Kennedy; N. Palmer. 1991. Patología de los animales domésticos. $5^{\mathrm{a}} \mathrm{ed}$. p 453-458. Ed. Hemisferio Sur. Uruguay.

7. López, H. 1983. Incidencia de la Hematuria Enzoótica del ganado vacuno en la provincia de Oxapampa. Tesis de Bachillerato. Fac. Cienc. Agropec., Univ. Nac. Daniel Alcides Carrión. Oxapampa. $50 \mathrm{p}$.

7. Marcal, W.S.; L. Gaste. 1991. Perspectiva terapéutica para la hematuria enzoótica de los bovinos - estudio clínico preliminar. Anales XLVI Conf. Anual de la Sociedad Paulista de Medicina Veterinaria, Brasil. p 48.

9. Marin, R. 2001. Bovine enzootic haematuria and upper digestive tract carcinoma as expresión of natural chronic toxicosis by consumption of Pteridium aquilinum in Argentina. ${ }^{\text {th }}$ International Symposium of Poisonus Plants. Glasgow, Escotland.

10. Moulton, J.E. 1978. Tumors in domestic animals. $2^{a}$ ed. p 295-305. University of California. Los Angeles, USA.

11. Mugera, G.M.; P. Nerito. 1968. Tumours of the urinary bladder and liver associated with enzootic haematuria in Kenyan cattle. Vet. Rec. 83: 457-459.

12. Niwa, H., M. Ojiva; K. Wakamatsu; K. Yamada; S. Ohba; Y. Saito; I. Hirono; K. Matsushita. 1983. Stereochemistry of ptaquiloside, a novel norsesquiterpene glucoside from bracken, Pteridium aquilinum var latiusculum. Tetrahedron Lett. 24: 5371-5372.

13. Olson, C.; A.M. Pamucku; D.F. Brobst. 1965. Papilloma-like virus from bovine urinary bladder tumors. Cancer Research 25: 840-849.

14. Pamukcu, A.M. 1974. Tumours of the urinary bladder. En: International histological classification of tumours of domestic animals. Bull. Wld. Hlth. Org. Vol. 50, Cap. 4. World Health Organization. Geneva, Switzerland.

15. Pamukcu, A.M; E. Erturk; J.M. Price; G.T. Bryan. 1972. Lymphatic leukemia and pulmonary tumors in female Swiss mice fed bracken fern (Pteris aquilina). Cancer Research 32: 1442-1445.

16. Pamukcu, A.M.; J.M. Price; G.T. Bryan. 1976. Naturally occurring and braken-ferninduced bovine urinary bladder tumors. Clinical and morphological characteristics. Vet. Pathol. 13: 110-122.

17. Radostits, O.M.; C.C. Gay; D.C. Blood; K.W. Hinchcliff. 2002. Medicina veterinaria: tratado de las enfermedades del ganado bovino, ovino, porcino, caprino y equi-

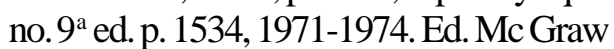
Hill-Interamericana. Madrid, España.

18. Spiegel, M.R. 1991. Estadística. $2^{\mathrm{a}} \mathrm{ed}$. p 186-88. Mc Graw Hill. EEUU.

19. Torres, J. 1990. Prevenga la hematuria en su ganado. Rev. El Cebú (Colombia). 253: 37.

20. Velarde, C. 1991. Manual de enfermedades del ganado vacuno y ovino en la selva central. p 54. Proy. Esp. Pichis Palcazu. Oxapampa.

21. Villafañe, F.; A. Orrego; G. González; R. Puerta; E. Báez. 1979. La papilomatosis faríngea bovina en Colombia. Rev. Acovez (Colombia) 3: 7-11.

22. Wiesner, E. 1973. Enfermedades del ganado bovino. p 207. Ed. Acribia. Zaragoza, España. 